Acta Poetica $26(1-2)$

PRIMAVERA-OTOÑO

2005

\title{
Gestos de la letra: aproximación a la lectura y escritura en la tradición judía
}

\author{
Silvana Rabinovich
}

\begin{abstract}
El texto "Gestos de la letra: aproximación a la lectura y escritura en la tradición judía", intenta, a partir de algunos textos de Henri Meschonnic y Marcel Jousse, aproximarse a ciertas prácticas de lectura en la tradición judía, a la relación entre lo oral y lo escrito — en el marco de la ética heterónoma- y su posible aporte a las prácticas de lectura en el medio académico.

Based on texts by Henri Meschonnic and Marcel Jousse, this paper reviews some traditional Jewish reading customs, as well as the links between orality and writing in the context of heteronomous ethics and its possible contribution to the reading process in an academic context.
\end{abstract}



Acta Poetica 26 (1-2)

PRIMAVERA-OTOÑO

2005

Silvana Rabinovich

Instituto de Investigaciones Filológicas, UNAM

\section{Gestos de la letra: aproximación a la lectura y escritura en la tradición judía}

\section{Lenguas y melodías nómadas}

¿Cómo se lee en el marco de la tradición judía? Aparentemente se trata de una pregunta sencilla, que espera por respuesta la descripción de ciertas prácticas tradicionales, variables de acuerdo con la geografía por tratarse de un pueblo que se halla en la diáspora y desde hace siglos está en contacto con diversas culturas.

La primera respuesta que surge tiene el carácter de una prescripción: la Torá se debe leer bejavruta. Pero esta respuesta contiene dos términos extranjeros: el primero es hebreo, designa al Pentateuco, pero literalmente significa "enseñanza", la raíz hebrea $\mathrm{YRH}^{1}$ designa tanto a los padres como a los maestros, el nombre Torá ${ }^{2}$ entonces no es traducible por "Ley" ni — como veremos más adelante- mucho menos, por "Es-

\footnotetext{
${ }^{1}$ La lengua hebrea es consonántica, y tiene raíces triádicas (el hebreo moderno incluye raíces de cuatro letras). Hay dos semivocales que son equivalentes e intercambiables cuando se encuentran en una raíz: es el caso de la Y que se transforma en $\mathrm{O}$ dentro del sustantivo Torá (Horim son padres, Morim son maestros).

${ }^{2}$ La Torá designa a los cinco primeros libros de la Biblia: Génesis, Éxodo, Levítico, Números y Deuteronomio.
} 
crituras". El segundo término es arameo, y describe una situación que podría traducirse como "en compañía" o incluso "en amistad" (esto no evita la discusión o majlóket, que anima siempre a la lectura conjunta). La prescripción talmúdica (del Tratado de Berajot) dice "bejavruta o bemituta", que se traduce como "en compañía o la muerte". Además, "bejavruta" no sólo indica la prohibición de leer a solas el texto, sino que en la práctica prescribe leerlo en voz alta (no por necesidad, ya que la alfabetización en esta tradición se inicia a los tres años y el compañero siempre sabe leer; se trata de leer escuchando el texto, su ritmo en la voz del otro, o a veces en la voz de uno mismo pero, al pronunciar la palabra del Otro, la propia voz aparece como ajena). Junto a otro, al prójimo, se trata de preguntar al texto.

Sabemos que desde el siglo XIV se registra en Occidente la prescripción de lectura en voz baja en la biblioteca, que se refuerza más tarde con la invención de la imprenta. ${ }^{3}$ La pregunta es por qué, si los círculos religiosos judíos se benefician de las versiones impresas del texto sagrado, la obligación de leer entre dos y en voz alta nunca caducó. No es por razones instrumentales ni tampoco obstinaciones tribales, hay algo en la concepción de la lectura que permite pensar que tal vez se trate del sentido hebreo del verbo leer cuya raíz $\mathrm{KRA}^{4}$ designa también el llamado, y lleva implícita la voz. La tradición judía concerniente a las formas de leer no sucumbió a los encantos de la lectura autónoma y solitaria. El acto de leer en tanto llamado se relaciona con la heteronomía, que puede explicarse levinasianamante como la "interpelación del otro": una evocación (y a veces irrupción) de la palabra del Otro (palabra divina), que a su vez interpela al otro (al compañero).

\footnotetext{
${ }^{3}$ Saenger 2001, 239-240.

${ }^{4}$ La raíz es $\mathrm{K}$ (kof) $\mathrm{R}$ (resh) A (alef, letra muda que prefiero representar con la vocal A y no con la $\mathrm{H}$ que normalmente representa a la $\mathrm{He}$, que es una $\mathrm{H}$ aspirada).
} 
Ahora bien, se trata hasta ahora de abordar la prescripción de leer bejavruta (que lleva implícita una proscripción mayor: la de leer a solas y en silencio). Pero esta prescripción de lectura generó a su vez (como toda lectura) una escritura particular.

Se abren entonces (por el momento, en el marco de este trabajo) dos puertas para entrar en esta tradición de lectura: la que indica la iniciación en el acto de leer con otro y la que recorre los escritos originados por estas lecturas y discusiones. En ambos casos se trata de preguntar acerca del estatuto de la voz y de la oralidad — esto concierne al ritmo, que se entiende a partir del gesto y del cuerpo.

Primera puerta: el cuerpo que lee

Bruriah encontró a un alumno que repetía en silencio. Lo pateó y le dijo: ¿Acaso no dice así: 'bien arreglado en todo y seguro' [II Sam, 23:5] — si está arreglado [dispuesto] con tus 248 miembros - se asegura [el pacto, se cuida], y si no - no se asegura? (Talmud, Tratado Eiruvin, 53, 54). ${ }^{5}$

Bruriah es la única figura femenina de la literatura talmúdica cuya estatura moral y pensamiento ha trascendido, era la esposa de Rabi Meir (s. II), conocida y respetada por su carácter y agudeza. La leyenda citada, en boca de esta mujer, da cuenta de la entrega de cada órgano o miembro del cuerpo en el acto de leer. Ella traduce ese fragmento de las postreras palabras del rey David en términos corporales, como indicación de una práctica de lectura, de un camino en el texto.

En el umbral de esta primera puerta, del cuerpo lector, resuena una vieja canción, que describe a los niños aprendiendo

\footnotetext{
5 Apud Bialik y Ravnitzky 2000, tomo I, 330. La traducción del hebreo es mía, las aclaraciones entre corchetes sirven para entender más ampliamente la traducción de la Biblia citada, todas las leyendas del Sefer Haagadá que aquí se citan son traducción mía.
} 
el alfabeto hebreo, en el jéder, lugar de lectura de la Torá equivalente a la escuela, con el maestro. ${ }^{6} \mathrm{El} \mathrm{Talmud} \mathrm{indica} \mathrm{iniciar}$ a los niños a la edad de tres años en el aprendizaje de las letras, a los cinco años en la lectura de la Biblia, a los diez en la Mishnáh y a los quince en el Talmud. ${ }^{7}$ En consonancia con la plegaria Shemá (Deut. VI 4-9) que comienza con el imperativo del verbo "escuchar" y prescribe transmitir — para guardar en la memoria - la unicidad de dios, el rabino de esta canción (rav significa "maestro", además de "grande" y "plural") les recomienda a los niños, "escuchen, recuerden por favor", o en otra parte les exhorta: "pongan el ojo, agucen el oído". El texto bíblico (Éxodo XX 15) conjuga ambos gestos inherentes a la lectura (ver y oír) aludiendo al pueblo que "vio las voces". El imperativo de la escucha (que a su vez es el del amor y el de la repetición que constituyen la enseñanza), trascrito del Deuteronomio, se encuentra cuidadosamente enrollado en las filacterias que - a la hora de la plegaria - el judío ata en torno a su cabeza y a su brazo izquierdo, y también dentro de la mezuzáh, esto es, un pequeño estuche que se clava en el marco de la puerta. La plegaria ordena escuchar la unicidad de Dios y amarlo, y repetirlo a los hijos y decir estas palabras al acostarse, al levantarse, al estar en la casa y también estando en camino "y las atarás por señal en tu mano, y estarán por frontales entre tus ojos; y las escribirás en las jambas de tu casa, y en tus puertas (de las ciudades)" (Deut. 6, 4-9).

Leer escuchando la palabra del Otro en la voz del otro (porque aun cuando se trata de mi voz, con ecos de Rimbaud esa palabra ajena recuerda que "yo es otro"), impide la intimidad con el texto que puede incurrir en la intimidación de la letra por parte del lector que se siente libre de someter al texto. No

${ }^{6}$ Cf. Apéndice 1: aparecen en él la canción original en yídish (y la versión hebrea) que se enseña a los niños cuando inician el estudio de la Torá. Se trata de la canción Der Alefbeis del compositor polaco Mark Warshawsky (s. XIX), con la traducción al español de Perla Sneh.

${ }^{7}$ Cf. Tratado de los Padres 5 (apud Bialik y Ravnitzky 2000, tomo I, 30). 
se trata sólo de la voz sino del ritmo, de la respiración del texto, que — siguiendo a Henri Meschonnic — hace aparecer al sujeto en la trama de la letra. Este poeta - también traductor de textos bíblicos - define al texto como "actividad de enunciación", cuyo abordaje oral se entiende como "inscripción del sujeto que implica un modo específico de compromiso del lector que participa en el texto, tendiente a fundir el tiempo del texto y el tiempo del lector". ${ }^{8}$ Según este autor, esta característica concierne paradigmáticamente al texto bíblico, debido a la "organización pan-rítmica del lenguaje en el texto hebreo", que no presenta oposición entre prosa y poesía. ${ }^{9} \mathrm{El}$ ritmo, concerniente tanto a la voz como a la escritura, se define como "el movimiento de la voz en la escritura. Con él, no se escucha sonido, sino sujeto". ${ }^{10} \mathrm{El}$ Talmud prescribe la melodía y el ritmo en la lectura, sin este elemento, la transmisión es casi imposible:

Dijo Rabi Shfatiah que dijo Rabi Yojanan: todo aquel que lee sin melodía y repite sin música, sobre él está escrito: 'Y además, les he dejado andar en estatutos que no eran buenos y en preceptos en los cuales no podrían vivir'. (Eze, 20:25, Talmud de Babilonia, Tratado Meguilá, 32a) ${ }^{11}$

La prosodia, el ritmo de la lectura bíblica en hebreo - como bien nota Meschonnic_- ${ }^{12}$ se dice con la palabra hebrea tá'am, sustantivo que designa también el sentido del gusto. La lectura en voz alta de la Torá — poniendo en juego los cinco sentidos con el fin de reavivar la llama del Infinito Sentido-

\footnotetext{
${ }^{8}$ Meschonnic 1989, 256 [todos los textos originales del francés de Meschonnic y Jousse aparecen aquí traducidos por mí].

${ }^{9}$ Meschonnic 1989, 247.

${ }^{10}$ Meschonnic 1989, 270.

${ }^{11}$ Apud Bialik y Ravnitzky 2000, tomo I, 330. Las referencias bíblicas de todo este trabajo son tomadas de la traducción de Dujovne y Schalman, La Biblia, 1998.

12 Meschonnic 1989, 23.
} 
es una puesta en escena del cuerpo. La iniciación a la lectura se da en algunos medios tradicionales aún hoy a través de una vieja costumbre: se trata de escribir en miel sobre una pizarrita las letras del abecedario (de alef hasta tav), que cada niño debe aprender a reconocer con la lengua, repasarlas para que su primera aproximación a la Torá recuerde ese sabor dulce experimentado por el profeta Ezequiel quien, al obedecer el mandato de comer el rollo escrito por ambos lados, experimentó el sabor de la miel (Ezequiel III 3). Otra costumbre es presentar en una pizarra escrita con letras de miel o caramelo el versículo 103 del Salmo 119 que dice "¡Cuán dulces a mi paladar son Tus dichos; más que la miel a mi boca!”. El antropólogo jesuita Marcel Jousse concluye: "Para el medio de los recitadores palestinos, comer era repetir, comer era articular, comer era ritmar". 13

Lo oral remite a la boca (lat. Os, oris): en ella confluyen el gusto y la palabra. Esta última, por tratarse de la voz, también concierne al oído. Meschonnic remite a un estudio de caso en el que la palabra tiene que ver con el acto de devorar: se trata de los Tyokossi del Togo, ${ }^{14}$ que utilizan el mismo vocablo $d i$ para designar la acción de comer pero también contar un cuento; asimismo "comer el sexo de la mujer" es copular, "comer el juicio" es pronunciarlo, "comer la realeza" significa que el rey es entronizado, "comer la pobreza" equivale a ser pobre. Habría que tomar más en serio esta relación entre leer, repetir ${ }^{15}$ y comer, entre el saber y el sabor, que, como vimos,

\footnotetext{
${ }^{13}$ Marcel Jousse 1975, 53 (la traducción respeta el original “palestinien”, pero llama la atención porque este autor insiste en recuperar los nombres arameos y hebreos, y el nombre de la tierra de Palestina o Israel, en los tiempos bíblicos es Canaán, por lo que sería más adecuado el término "canaanita").

14 Cf. Meschonnic, 1989, 279 (remite al estudio de Diana Rey Hulman "Pratiques langagières et formes littéraires", en Goeroeg-Karady, Genders, Forms, Meanings: Essays in African Oral Literature, Paris, MSH, 1983).

15 Nótese que el verbo "repetir" alude tanto a la palabra reiterada, como también a la acción. Con relación a la digestión, por un lado significa volver a comer el mismo alimento; pero también designa el incómodo fenómeno del regreso inesperado de un sabor perteneciente a una comida digerida hace tiempo, es una es-
} 
en hebreo tienen un nombre en común: tá'am cuyo significado es "gusto" y a la vez "prosodia". La leyenda talmúdica que se cita a continuación da cuenta del recorrido de la lectura (en analogía con el alimento) que va de la boca a las entrañas:

Dijo Rav Ammi: ¿Qué es eso que se ha dicho: 'Porque será cosa deliciosa cuando las guardares en tus entrañas, cuando se establecieren conjuntamente sobre tus labios' [Prov. 22:18]? - ¿Cuándo serán deliciosas las palabras de la Torá? -En el momento en que las guardes en tus entrañas; ¿Y cuándo las guardarás en tus entrañas? - Cuando se establezcan conjuntamente sobre tus labios. (Talmud de Babilonia, Tratado Eiruvin, 54a) ${ }^{16}$

Segunda puerta: el estatuto de la Escritura (Torá escrita y Torá oral)

Dijo Rabí Shimon Ben Lakish: La Torá que le fue entregada a Moisés estaba escrita con fuego negro sobre fuego blanco, y se hallaba sellada, encuadernada y cosida con un manto de fuego, limpió (borró) la punta del instrumento de escritura con su pelo - y de ese mismo fuego tomó Moisés la luz de su rostro. (Talmud de Jerusalén, Tratado Shekalim) ${ }^{17}$

El sentido común nos tentaría a pensar que las letras negras son la Torá Escrita y la parte blanca del texto son las infinitas interpretaciones (inagotable Torá Oral). La explicación de Isaac el Viejo (esto es, el Ciego) dice: "la forma de la Torá escrita es la de los colores del fuego blanco, la forma de la Torá

pecie — si se me permite — de memoria siniestra del estómago. En general, la repetición no tiene buena fama y esto se relaciona con el cartesianismo: por un lado, se ha desvalorizado la memorización en favor del análisis (como si éste pudiese prescindir de la memoria...); por otro lado, la desobediencia del cuerpo es un reto a la autoridad (axiomática) de la glándula pineal.

16 Apud Bialik y Ravnitzky 2000, 330.

17 Apud Bialik y Ravnitzky 2000, 62. Asimismo, Scholem 1988, 53-55. 
oral, tiene apariencias cromáticas como de fuego negro" (Scholem 1988, 53). La figura se complica, hay que suspender el sentido común para acceder a esta explicación: el verdadero texto es lo blanco; las letras, son simple comentario (la sentencia del invidente se encuentra mezclada con verdad física: el blanco es suma de todos los colores, el negro sólo apariencia). Siendo el "fuego blanco" la Torá escrita, en cuya superficie no se discierne palabra impresa; las letras son ya "fuego negro", obtienen el sonido de la Torá oral: la letra visible no es de naturaleza escrita sino oral, es aparentemente escritura. La negra letra es voz. Pero hay más, escribe el ciego: "Por ello la Torá escrita no puede asumir ninguna forma corpórea, a no ser por medio de la fuerza de la Torá oral, o sea: sin ella no puede ser comprendida verdaderamente". De allí concluye Scholem la idea mística de que "en esta tierra, hablando con propiedad, no existe Torá escrita alguna" (Scholem 1988, 54).

En la alegoría de la letra de fuego leída por Isaac el Ciego se descubre un contrabando febril de lo oral en lo escrito, que lleva a los cabalistas hasta el cuestionamiento del estatuto mismo de la escritura según la observación de Scholem referida más arriba (o, en el caso que nos interesa, una sospecha en torno a la oposición oral/escrito). Pero esa no es la única interpretación. Najmánides ${ }^{18}$ centra su lectura en la continuidad del fuego y en el sentido de la letra que acaricia el Nombre y no olvidemos que el verbo liKRO significa tanto "llamar" y "nombrar" como "leer". La raíz KRA da lugar al acto de nombrar y de leer, a la vez que nombra al texto bíblico "Mikrá", y en este entrecruzamiento evoca a la voz:

Poseemos una tradición auténtica, según la cual toda la Torá está constituida por el conjunto de los Nombres de Dios. Así, las palabras que leemos también pueden ser distribuidas de una forma enteramente distinta. La Torá escrita 'fuego negro

${ }^{18}$ Exegeta español del siglo XII, citado por Ouaknin 1999, 116. 
sobre fuego blanco' significa precisamente que el texto estaba escrito sin corte alguno, secuencia ininterrumpida de la primera a la última letra. Esa escritura constituye un Nombre que puede ser subdividido en Nombres.

De esta diversidad de interpretaciones en torno a la escritura y a las maneras de leer, podemos notar que hay una constante: no existe lectura definitiva ni interpretación que cierre, hay un imperativo que debe obedecer cada lector estudioso, y es el de preguntar infatigablemente al texto, sin que haya jamás una respuesta concluyente. No hay ser humano en la tierra que pueda arrogarse un saber absoluto. La leyenda que sigue lo ilustra con crudeza:

Dijo Rav Yehuda, dijo Rav: cuando Moisés subió al cielo, encontró al Santo Bendito Sea sentado amarrando coronas a las letras. Dijo Moisés ante Él: Señor del mundo, ¿quién te hace detener en esta tarea? Le dijo: hay un hombre, que estará dentro de varias generaciones, cuyo nombre es Akiva Ben Yosef, que en el futuro va a inquirir e interpretar cada una de las coronas y los rizos de montañas de leyes. Dijo ante Él: Señor del mundo, muéstramelo. Le dijo: voltéate. Fue y se sentó en la octava fila - y [Moisés] no supo qué decían. Se debilitó su fuerza. Como llegó a un tema, le dijeron sus discípulos: Rabí, ¿de dónde usted lo infiere? Les dijo: 'es la halajá [conducta prescripta] dada a Moisés en el Sinaí'. Se le aclaró. Regresó ante el Santo Bendito Sea, dijo ante Él: Señor del mundo, ¡tienes un hombre como este y me das a mí la Torá! Le dijo: cállate, así se me ocurrió. Dijo ante Él: Señor del mundo, me mostraste su Enseñanza [Torá], muéstrame ahora su recompensa. Le dijo: voltéate. Se volteó y vio que pesaban su carne en una carnicería. Dijo ante Él: Señor del mundo, ¡esta es su Torá y esta es su recompensa! Le dijo: cállate, así se me ocurrió

(Talmud de Babilonia, Tratado Menajot). ${ }^{19}$

19 Apud Bialik, Ravnitzky 2000, tomo I, 178. 
Se sabe que la muerte de Akiva Ben Yosef tuvo lugar bajo el yugo romano (que había prohibido el estudio de la Torá), su carne le fue arrancada con peines de hierro. Sus enseñanzas, si bien fueron transmitidas y diseminadas a lo largo de las generaciones, no eximen a los lectores posteriores de la responsabilidad de seguir preguntando a los textos. Moisés fue el transmisor, pero (como ocurre siempre en la transmisión) transmitió mucho más de lo que sabía (dice la tradición que él recibió toda la Torá Escrita y la Torá Oral). El relato descubre - entre otras cosas— ${ }^{20}$ que el saber individual y definitivo es ilusorio, que el saber no es poseído, sino que pasa a través del que estudia y lo transmite, se trata de una tarea conjunta y permanente de construcción. Además, - - y el cruel final de Rabí Akiva lo ejemplifica- (al modo del Eclesiastés I, 18): el saber (en este caso, el estudio de la Torá) comporta dolor ${ }^{21}$ (en el caso de Rabí Akiva, causa la persecución y la muerte).

La lectura como tarea interpretativa, como trabajo conjunto de discusión en la tradición, se dio a lo largo de siglos y sigue existiendo. Una vez canonizado el texto bíblico (en el que se encuentra el Pentateuco, considerado Torá Escrita (Torá shebijtav), desde el siglo II antes de la era cristiana, hasta mediados del siglo vi de nuestra era ${ }^{22}$ se desarrolló la Torá Oral (Torá shebeal pe), conocida como Talmud. La primera parte de esta obra, que consiste en interpretaciones de la Ley escrita, fue elaborada por generaciones de estudiosos conocidos como Tanaím y fue redactada en hebreo en el siglo II d.C. por Rabí Yehudah Hanasí. Una vez sellada la Mishná, empezó a escribirse la Guemará, que es un complejo comentario de la Mishnáh y que fue escrita por estudiosos conocidos como amoraítas paralelamente en la tierra de Israel y en Babilonia. Este

\footnotetext{
${ }^{20}$ Sin duda se trata una vez más (como en el libro de Job) de la imposibilidad humana para captar los criterios divinos.

${ }^{21}$ En el apéndice, titulado "la letra terapéutica", trataremos otros aspectos de la relación entre la lectura y el dolor.

22 Todas las fechas y cifras fueron consultadas en Ouaknin 1999, 50 y ss.
} 
segundo corpus de interpretaciones, que integra Mishnáh y Guemará, dio lugar a dos versiones del Talmud: el Talmud de Jerusalén (redactado en Tiberíades hacia el año 380) y el Talmud de Babilonia (finalizado hacia el año 500, impreso en versión completa por primera vez en Venecia, 1520-1523). Lo que llama la atención es que se trata de aproximadamente 6000 páginas impresas (de una impresión compleja ya que la disposición del texto es concéntrica) que siguen llamándose Torá Oral. El estatuto de lo oral es lo que exige una especial atención en esta tradición de lectura. Algo de esto se lee en el estilo dialógico del Talmud, de explícita polifonía, que no sólo nombra a los autores de los dichos y los cita en estilo directo, sino que exige a quien los lee (por causa de la puntuación: paréntesis, guiones, dos puntos) variar constantemente los tonos y modelar las pausas. En este marco, el poeta traductor de textos bíblicos Henri Meschonnic propone salir de la lógica binaria:

La oposición de lo oral a lo escrito confunde lo oral y lo hablado. Pasar de la dualidad oral/ escrito a una repartición triple entre lo escrito, lo hablado y lo oral, permite reconocer lo oral como un primado del ritmo y de la prosodia, con su semántica propia, organización subjetiva y cultural de un discurso, que puede realizarse tanto en lo escrito como en lo hablado. ${ }^{23}$

Este triple modelo, explica la frontera permeable entre oralidad y escritura que, en un marco de lectura bejavruta, aborda la lectura en voz alta de la Enseñanza Oral y de la Escrita. El autor va más lejos, no se queda en el marco de los textos religiosos, sino que encuentra esta vulnerable frontera en la literatura:

\footnotetext{
23 Meschonnic 1989, 236 “L'opposition de l'oral à l'écrit confond l'oral et le parlé. Passer de la dualité oral/écrit à une répartition triple entre l'écrit, le parlé et l'oral permet de reconnaître l'oral comme un primat du rythme et de la prosodie, avec sa sémantique propre, organisation subjective et culturelle d'un discours, qui peut se réaliser dans l'écrit comme dans le parlé".
} 
Se vuelve pues no solamente posible, sino necesario, concebir la oralidad ya no más como la ausencia de escritura y solamente como el pasaje de la boca al oído, antaño interiorizado, hoy valorizado-psicoanalizado por algunos como pulsión liberadora, que permanece en el dualismo como la blasfemia permanece en la religión. No, sino como una organización del discurso regida por el ritmo. La manifestación de una gestualidad, de una corporalidad y de una subjetividad en el lenguaje. Con los medios de lo hablado en lo hablado, con los medios de lo escrito en lo escrito. Y si algo muestra que hay de lo oral en lo escrito, y que lo oral no es lo hablado, es la literatura. ${ }^{24}$

Levinas, por su parte, respecto a la lectura bíblica en la tradición judía, dice escuchar la resonancia de "otra voz, una sonoridad segunda cubriendo o desgarrando la primera", 25 que tiene que ver con la dimensión poética del texto, allá donde se encuentra un pasaje entre el versículo y el verso.

La recuperación de lo oral como parte de la escritura (entendido como ritmo) da lugar a una puesta en práctica de la lectura que tiene implicancias éticas fuertes. Este otro modo de leer, no se queda en los límites del estudio de una cultura determinada o de una religión sino que exige reflexionar acerca de esta práctica en nuestra civilización escrita. Se trata de una puesta en escena de la alteridad y de la mal afamada heteronomía ${ }^{26}$ en la constitución misma de la subjetividad cobrando cuerpo en la voz y en la escucha:

\footnotetext{
24 Meschonnic 1989, 246 "Il devient donc non seulement possible, mais nécessaire, de concevoir l'oralité non plus comme l'absence d'écriture et le seul passage de la bouche à l'oreille, jadis intériorisé, aujourd'hui valorisé - psychanalysé par certains comme pulsion libératrice, qui reste dans le dualisme comme le blasphème reste dans la religion. Non, mais comme une organisation du discours régie par le rythme. La manifestation d'une gestuelle, d'une corporalité et d'une subjectivité dans le langage. Avec les moyens du parlé dans le parlé, avec les moyens de l'écrit dans l'écrit. Et si quelque chose montre qu'il y a de l'oral dans l'écrit, et que l'oral n'est pas le parlé, c'est bien la littérature".

25 Levinas 1982, en "De la lecture juive des écritures", 137 (las citas a este libro están traducidas por mí).

${ }^{26}$ El término "heteronomía" alude a la ética de Emmanuel Levinas, pero también a muchos otros autores, tanto de filosofía como de literatura, entre los que
} 
La oralidad es un trabajo, de sí mismo sobre sí mismo y para con los otros. El ritmo, entonces, es una misión del sujeto. La experimentación imprevisible de la alteridad sobre la identidad. Es por esto que la oralidad y el ritmo son la materia y lo que está en juego en la modernidad. Salir de Platón. Y de la casa de Hegel.

La escritura, paradójicamente, es la mejor ilustración de la oralidad. Su realización por excelencia. ${ }^{27}$

\section{Leer el gesto: convocar (oralidad de la escritura)}

Uno de los nombres comunes de la Biblia, en hebreo, es $M i$ krá, que significa en el uso bíblico 'convocación, lectura, celebración de una fiesta' y que, en el uso post-bíblico y moderno, designa la Biblia. Esta lectura no se opone a la escritura. Mikrá coincide entonces con lectura. Mikrá sostiene conjuntamente la oralidad y la colectividad. En ella, la noción de escrito es técnica: los Escritos, ketuvim no son allí la Escritura, sino que tienen un valor delimitado por torá y neviim, Profetas. 28

pueden nombrarse: Franz Rosenzweig, Eugen Rosenstock-Huessy, Mijaíl Bajtín, Paul Celan. El calificativo de "mal afamada" tiene que ver con un privilegio de la moral autónoma que se da tanto en la ética kantiana como en su interpretación cotidiana. En la tradición filosófica esto se debe a una preeminencia de la identidad sobre la alteridad que puede situarse ya en Platón y que, tal como lo enuncia Meschonnic, es el dominio de Hegel.

27 Meschonnic 1989, 235 "L'oralité est un travail, de soi sur soi et vers les autres. Le rythme, alors, une mission du sujet. L'expérimentation imprévisible de l'altérité sur l'identité. C'est pourquoi l'oralité et le rythme sont la matière et l'enjeu de la modernité. Sortir de chez Platon. Et de la maison de Hegel.

L'écriture, paradoxalement, est la meilleure illustration de l'oralité. Sa réalisation par excellence".

${ }^{28}$ Meschonnic 1975, 536 "L'un des noms communs de la Bible, en hébreu, est Miqra, qui signifie dans l'usage biblique 'convocation, lecture, célébration de fête' et qui, dans l'usage postbiblique et moderne, désigne la Bible. Cette lecture ne s'oppose pas à l'écriture. Miqra tient ensemble l'oralité et la collectivité. La notion d'écrit y est technique: les Écrits, ketuvim, n'y sont pas l'Écriture, mais ont une valeur délimitée par tora et neviim, Prophètes". 
Esta cita de Meschonnic expone el sentido de la raíz de la lectura que atraviesa el cuerpo del texto bíblico (Mikrá), dejando en claro la oralidad y la colectividad inherentes a la raíz verbal KRA: llamar (en voz alta), nombrar, siempre implica una relación con el otro. El texto bíblico no encuentra en su denominación hebrea asidero para ser llamado "Escrituras", de las tres siglas que conforman el acrónimo TaNaKH (Torá o Pentateuco, Neviím o Profetas y Ktuvím que se traduce literalmente por "Escritos") sólo el nombre de la tercera parte se compone de la raíz de la escritura (KTV) conjugada como participio pasado masculino plural. El nombre Mikrá (lectura, llamado, convocatoria, anuncio, locución) revela la oralidad de la escritura y de la Torá Escrita, de ahí el imperativo de la lectura bejavruta. Leer es respirar la palabra del otro, acompañar sus pausas y su ritmo, recibiendo su aliento, acoger y transmitir su gesto. He aquí la heteronomía en el acto de leer. Leer evocando el gesto, siendo llamado por el texto, convocando a otros. La boca es el lugar de la transmisión, memoria del pacto, tal como enuncia el versículo (Isaías 59, 21): "YY en cuanto a Mí, éste será Mi pacto con ellos' dice el Señor: 'Mi espíritu que está sobre ti, y Mis palabras que he puesto en tu boca, no se apartarán de tu boca, ni de la boca de tu simiente, ni de la boca de la simiente de tu simiente, dice el Señor, desde ahora en adelante y para siempre",.

El lector-transmisor es una suerte de médium, que presta su boca y vocaliza la palabra escrita. Emmanuel Levinas se refiere en diversos textos a la dimensión profética de la palabra ${ }^{29}$ (que no es un don especial sino un estado de hiperestesia en la recepción del otro que se da en el lenguaje, que desde siempre se encuentra precedido por la escucha). El filósofo recurre a la metáfora de la respiración para referir al lenguaje, proceso en el que la inspiración (acogida de lo otro) es la contraparte de

\footnotetext{
${ }^{29}$ Cf. Levinas, Autrement qu'être ou au-delà de l'essence (trad. esp. De otro modo que ser o más allá de la esencia, Salamanca, Sígueme, 1997).
} 
la expiración (o palabra dada al otro), podríamos decir que el acto de "dar la palabra al otro" resume ambos movimientos: cederle la palabra, acogerla dejándose inspirar por ella, y a la vez, comprometerse a través de la palabra propia. Así, para Levinas, el lenguaje es inspiración:

Podemos preguntarnos si el hombre, animal dotado de palabra, no es, ante todo, animal capaz de inspiración, animal profético. Podemos preguntarnos si el libro, en tanto libro, antes de hacerse documento, no es la modalidad bajo la cual lo dicho se expone ante la exégesis y la llama, y donde el sentido, inmovilizado en los caracteres, desgarra ya la textura que lo sostiene. ${ }^{30}$

Levinas afirma que los procedimientos de lectura de la tradición judía sugieren que "su poder-decir supera su querer-decir", que el texto contiene más de lo imaginado, "que un excedente de sentido, tal vez inagotable, queda encerrado en las estructuras sintácticas de la frase, en sus grupos de palabras, en sus vocablos, fonemas y letras, en toda esta materialidad del decir, virtualmente siempre significante". ${ }^{31}$ La lectura es inspiración, dimensión profética que se actualiza en la práctica bejavruta, donde se pone en acto la heteronomía. La escucha del texto obliga al lector a inquirir la letra junto con su compañero. De este modo, el temor de Sócrates respecto a la mudez de la escritura, ${ }^{32}$ expresado en el Fedro, queda conjurado desde la ética heterónoma. El autor (todo aquel que trans-

30 “'On peut se demander si l'homme, animal doué de parole, n'est pas, avant tout, animal capable d'inspiration, animal prophétique. On peut se demander si le livre, en tant que livre, avant de se faire document, n'est pas la modalité sous laquelle le dit s'expose à l'exégèse et l'appelle et où le sens, immobilisé dans les caractères, déchire déjà la texture qui le tient" (136-137), en Levinas 1982, "De la lecture juive des écritures", pp. 125-142.

${ }^{31}$ Levinas 1982, 135.

32 Platón 1995, v. 375d, 321: "Porque es impresionante, Fedro, lo que pasa con la escritura, y por lo tanto se parece a la pintura. En efecto, sus vástagos están ante nosotros como si tuvieran vida; pero, si se les pregunta algo, responden con el más altivo de los silencios". 
mite en general, considerando que el lenguaje no puede reducirse a una función instrumental) dice mucho más de lo que cree decir: al abrirse hacia el otro es desbordado por aquella palabra que va a darle y que a la vez le viene de otra parte. En términos cabalísticos: la parte blanca del texto susurra sentidos infinitos y deben aguzarse todos los sentidos para acogerlos. Si quien transmite oralmente (pero también por escrito), se encuentra siempre excedido por el sentido de aquello que transmite, debe tomarse en cuenta que el lenguaje (irreductible a la propiedad) no se reduce a las palabras sino que el gesto también habla y escribe. Se trata entonces de hacer el esfuerzo a fin de leer el gesto.

El jesuita Marcel Jousse refiere a una "lógica gestual" inherente al medio palestino o canaanita y aclara que la abstracción no es una antítesis de lo concreto, que la abstracción intelectual se engendra en el gesto concreto. ${ }^{33}$ Por su parte, en la puntuación Meschonnic encuentra el gesto y lo oral de la poética de un texto. ${ }^{34}$ Jousse insiste en el gesto mímico como transmisor y origen de la escritura, inventa un neologismo: en lugar del lenguaje oral, el "corporage" [corporaje] obedece a aquello que expresa. ${ }^{35}$

El niño, así como el hombre primordial, juega, con las sombras chinescas, a la escritura viviente. Las sombras, espontáneamente, han inventado la escritura. En cuanto el sol sale, en cuanto un fuego se enciende, he ahí la escritura inventada. ${ }^{36}$

33 Cf. Jousse 1974, 89, 110.

34 Meschonnic 1989, 252.

35 Jousse 1974, 87-88: “On n'est pas aphasique quand, pour s'exprimer, l'on se sert du 'Corporage', et non pas du Langage oral, et que toute la gesticulation globale est obédientielle aux choses à exprimer. C'est cela que nous montrent à chaque instant les grands Nabis d'Israël et c'est cela que ne nous avaient pas expliqué nos exégètes d'hier".

36 Jousse 1974, 105 'L'enfant, comme l'homme primordial, joue, avec les ombres chinoises, à l'écriture vivante. Les ombres, spontanément, ont inventé l'écriture. Dès que le soleil se lève, dès qu'un feu s'allume, voilà l'écriture inventée". Basta con ver el cuadro de la evolución del alfabeto para entender esta idea del antropólogo jesuita (cf. anexo 3). 
Leer sería entonces estar atento a las semejanzas, escuchar sugerencias del texto blanco y de su voz que son las letras negras. Las firmes letras impresas se descubren genealógicamente como sombras, y la fe desmedida en la vista reconoce que necesita aguzar del oído. Leer en voz alta implica escuchar la letra, ser solicitado en el acto de lectura como complemento a la expresión bíblica ya citada (Éxodo XX, 15) que describe al pueblo temblando al "ver las voces". Leer, desde esta perspectiva, equivaldría a "ver voces". Poner el cuerpo en el acto de leer exige estar dispuesto a dejarse estremecer por los textos.

Tras largos siglos de lectura académica a solas y en voz baja, esta lejana costumbre de leer puede pensarse fuera de las fronteras de la religión. Así, se trata de percibir la calidez del aliento del otro, re-significando la noción de sujeto. De este modo, desde la heteronomía, se revela la inspiración inherente a las prácticas de lectura y escritura. Entonces se ponen en escena la polifonía y la multiplicidad de lenguajes que irrigan los textos. La literatura abre esa posibilidad, a propósito de la infinita lectura del gesto, Benjamin escribía: ${ }^{37}$

[...] el gesto era para Kafka sin duda lo más inabarcable. Cada uno de ellos significaba de por sí un telón, o más aún, un drama. [...] retira los soportes tradicionales del ademán para quedarse con un objeto de reflexión interminable.

${ }^{37}$ Benjamin 1999, 144 y 145. 


\section{Apéndice 1: La letra terapéutica}

He aquí la vieja melodía que acompañó las presentes lecturas (primero la versión original en yídish, luego la versión hebrea y sus respectivas traducciones) que describe la iniciación a la lectura. Decidí citar ambas versiones por las diferencias que presentan entre ellas:

\section{Der alefbeis \\ Letra y música: \\ Mark Warszawski \\ Oifn pripetchik brent a fáierl \\ un in shtub iz héiz \\ un der rebe lernt kleine kínderlej \\ dem alefbeis \\ Estribillo: \\ Zet'sze kinderlej, guedenkt sze táiere \\ vos ir lernt dó \\ zog'sze nój a mol un take nój \\ a mol kometz-alef: "o" \\ Lernt kinder mit grois jeshek, \\ azoi zog ij aij on: \\ ver s'vet guijer fun aij kenen ivre der bakumt a fon}

\section{El alfabeto $^{38}$}

En el pripechik ${ }^{39}$ arde un fueguito

y en la casa hace calor

y el rebe le enseña a los más chiquitos

el alefbeis.

Observen, chicos, recuerden mis queridos, lo que aprenden aquí, digan una y otra vez: kometz, alef: ${ }^{40}$ "o"

Estudien chicos con muchas ganas, esto les prometo: el que más rápido sepa hebreo recibe como premio una banderita

\footnotetext{
38 Traducción al español de Perla Sneh.

${ }^{39}$ Es una parte del horno que se encendía para calentar el ambiente.

${ }^{40}$ Es decir: una letra alef con kamátz (vocal) se lee "o".
} 
(estribillo)

Lernt kinder, hot nisht moire Estudien, chicos, no tengan miedo;

ieder onheib iz shver todo comienzo es difícil

glick iz der vos hot guelernt toire- Feliz de aquel que ha estudiado la Torá

tzi darf der mentsh noj mer?

¿Qué más puede necesitar un hombre?

(estribillo)

Ir vet kinder elter vern,

Chicos, cuando crezcan

vet ir alein farshtein van a entender por sí mismos

vifl in di oises lign trern cuántas lágrimas yacen en estas letras

un vifl gevein.

y cuánto llanto

(estribillo)

$\mathrm{Az}$ ir vet kinder dem gules shlepn un oisguemitchet zain

Chicos, cuando estén agotados zolt ir fun di oises koiej shepnkukt in zei arain! de cargar con la golá $^{41}$ tomen fuerzas de estas letras busquen en ellas

(estribillo)

Oifn pripetchik brent a faierl

En el pripechik arde un fueguito

un in shtub iz heiz

y en la casa hace calor

un der rebe lernt kleine kinderlej

dem alefbeis

y el rebe le enseña a los más chiquitos

el alefbeis

${ }^{41}$ Entiéndase por golá: diáspora. 
Versión hebrea:

Jeder katan tzar vejamin

Veal hakiráh esh

Sham harabi et talmidav

Moré alef bet

Et toratí yaldei jémed

Shimu, zijru na!

Imrú shenit vejazuru:

Kamatz alef: o

Simu ayn, hatu ozen

Al hakatuv po

Mi sheykrá heitev ivrit

Deguel etén lo.

Et toratí yaldei jémed...

Kol hatjalot tamid kashot

Ajar yekel meod.

Ashrei mi shelamed Torah

Mah leyehudi od?

Et toratí yaldei jémed...

Et tazkinu af tavinu

Baotyot sham
Traducción del hebreo: ${ }^{42}$

En un jeder ${ }^{43}$ pequeño, estrecho y cálido

Sobre el mechero arde el fuego

Allí el rabí a sus alumnos

Enseña el alfabeto

Mi Torá, niños hermosos

Escuchen, recuerden por favor!

Digan por segunda vez y repi-

tan:

Kamatz alef: ${ }^{44} \mathrm{O}$

Pongan el ojo, agucen el oído A lo que está escrito aquí

Al que lea bien hebreo

Le daré una banderita.

Mi Torá, niños hermosos...

Todos los comienzos son difíciles

Después va a facilitarse mucho. Dichoso el que estudia la Torá ¿Qué más necesita un judío?

Mi Torá, niños hermosos...

En el tiempo que envejezcan también comprenderán

En las letras de allá

\footnotetext{
${ }^{42}$ La traducción es mía.

43 La palabra hebrea designa normalmente una habitación, pero pronunciada según el acento ashkenazí (heredero del yídish) significa el aula en que el maestro enseña la Torá a los niños.

${ }^{44}$ Kamatz es la vocal A que en el acento ashkenazí se lee O, alef la letra muda que permite su escritura. El kamatz da a la alef phoné mientras que la alef le da al kamatz, en esta lengua consonántica, la posibilidad de la grafía.
} 
Kama dmaot jamot tojen

Vejama najlei dam.

Et toratí yaldei jémed...

Et bagalut tis'u oljem

Af teanju mar

Beotyot az tevakshu

Nojam mikol tzar.

Et toratí yaldei jémed...
Cuántas lágrimas de contenido caliente

Y cuántos arroyos de sangre. Mi Torá, niños hermosos...

En el tiempo del exilio van a llevar su yugo

También suspirarán amargamente

En las letras pedirán

Consuelo de toda estrechez

Mi Torá, niños hermosos...

Vimos en la leyenda de Rabí Akiva el dolor y la muerte que advienen cuando la letra atemoriza al imperio en turno. Vimos también en esta canción, las capacidades terapéuticas de la letra, que es un bálsamo para el dolor del exilio. La letra vive en el gesto y cada lectura bejavruta le insufla un nuevo aliento, como podemos ver en la leyenda que sigue donde se recorre el alfabeto completo con las enseñanzas de la Torá:

"Dijeron los sabios a Rabí Josué hijo de Levi: vinieron niños hoy al beit hamidrash y dijeron cosas, que ni siquiera en tiempos de Josué hijo de Nun se habían dicho de esa forma:

Alef Bet: aprende el entendimiento (Alef bináh)

Guimel Dalet: recompensa a los pobres (Gmol dalim)

¿Cuál es la razón del pie de Guimel simple respecto de Dalet? Que así es el modo de quien hace el bien al prójimo (Gomel Jasadím), correr detrás de los pobres.

Y cuál es la razón del pie de Dalet simple respecto de Guimel? — “que se inventará a sí mismo" (recibirá sin dificultar al que da).

Y cuál es la razón del rostro de Dalet de espaldas a Guimel? - Que le dé pudorosamente (de manera anónima), para que no se avergüence delante suyo. 
Hei Vav: Es el nombre del Santo Bendito Sea (HW).

Zain Jet, Tet Yod, Kaf Lamed: si actúas así el Santo Bendito Sea te alimenta (zan) y te hospeda (jan) y te mejora (tov) y te da herencia (yerusháh) y te ata una corona (keter) para el mundo venidero (leolam habá).

Mem: abierta, mem cerrada — dicho (maamar) abierto, dicho cerrado [las palabras de la Torá]

Nun: agachada, ${ }^{45}$ nun simple — fiel (ne'eman) agachado, fiel simple.

Samej Ayn: Apoya a los pobres [smoj 'aniím]

$\boldsymbol{P e}$ : agachada, pe simple — boca (pe) abierta, boca cerrada.

Tzadi: inclinada, tzadi simple — justo [tzadik] sometido, justo simple [aquel que se somete al imperio de la justicia en este mundo y es modesto, en el mundo venidero será simple y erguido].

Kof: sagrado [kadosh], Resh —malvado [rashá]

¿Cuál es la razón por la cual Kof no da la cara a $\boldsymbol{R e s h}$ ? —Dijo el Santo Bendito Sea: no puedo mirar al malvado.

¿Y cuál es la razón por la cual la tilde de Kof está al revés que Resh? Dijo el Santo Bendito Sea: si se arrepiente le amarro una corona como a él.

¿Y cuál es la razón por la cual el pie de Kof está colgado? Si se arrepiente vendrá y entrará.

Shin: mentira [shéker], Tav: verdad [emét].

¿Y cuál es la razón por la cual las letras de "mentira" son cercanas y las de "verdad" lejanas [la shin es inicial de la palabra "shéker" pero la tav se sitúa al final de la palabra "emét"]?

- La mentira se encuentra y la verdad no se encuentra.

¿Y cuál es la razón por la cual la mentira se mantiene en un solo pie y la verdad se acuesta? [las letras reposan como la luna y su asiento es bello] — La verdad se mantiene y la mentira no resiste

(Agadah, leyenda talmúdica, Tratado Shabat, 104) ${ }^{46}$

\footnotetext{
${ }^{45}$ Las letras que aparecen como "agachadas" (o inclinadas) es porque al final de una palabra se modifican generalmente pasando el renglón hacia abajo.

${ }^{46}$ Apud Bialik y Ravnitzky 2000, 329, traducción mía del hebreo.
} 
Hay varios puntos interesantes en el relato:

a) Fueron los niños quienes se lo enseñaron al maestro. Aun el discípulo más pequeño, aquel que aprende el alfabeto, puede enseñar a su maestro.

b) Un maestro que enseña lo más elemental puede siempre aprender de sus discípulos.

c) No fue uno solo quien leyó de esta manera la letra, "vinieron niños", dice el texto.

d) Aprender las letras abre la posibilidad para acceder a los principios morales de la Torá. En este sentido, la posibilidad de leer, es una puerta abierta a la ética.

Para concluir, en esta leyenda, que ilustra el hallazgo del gesto en la letra, convergen varios de los elementos que aparecieron a lo largo de este trabajo.

a) La idea de Jousse, que atribuye el origen de la escritura a las sombras chinescas, derivada de las capacidades infantiles para percibir el gesto y la enseñanza en la letra.

b) La posibilidad de tomar el pulso al texto, buscando el ritmo, y a través de la voz, escuchar la letra, tal como sugiere Meschonnic.

c) Poniendo en escena la heteronomía: dejándose inspirar por la letra, dejándose enseñar por el discípulo (aun por el más joven, aun en el tema más simple), tal como sugiere Levinas.

d) Por último, toda esta dramatización de la Torá (enseñanza) o Mikrá (lectura, llamado) en el cuerpo de las letras es posible junto con otros, prestando oídos a la "sonoridad segunda" que recuerda Levinas. 


\section{Apéndice 2:}

He aquí otra canción que evoca (entre los judíos orientales) la iniciación a la lectura de la Torá, según otras costumbres.

\section{Etzlenu biKfar Todra}

Yehoshua Sobol, Shlomo Bar

Etzlenu bikfar Todra

Shebelev harei haAtlas

Hayu lokjim et hayéled

Shehiguia leguil jamesh

Keter prajim osim lo.

Etzlenu biKfar Todra

Keter barosh malbishim lo

Shehiguia leguil jamesh.

Kol hayeladim barejov

Jaguigá gdolá orjim lo

Shehiguia leguil jamesh.

Etzlenu bikfar Todra

Veaz et jatan hasimjá

Shehiguia leguil jamesh

Etzlenu bikfar Todra

Majnisim lebeit haknéset

Vekotvim lo al luaj shel etz

Bidvash mealef ad tav

Et kol haotiot bidvash

Veomrim lo: javivi lakek

Vehayta tora shebapeh metukah

Kmo taam shel dvash

Etzlenu bikfar Todra

Shebelev harei haAtlas
En nuestra aldea, Todra

en el corazón de los montes

Atlas

solían tomar al niño

que llegaba a la edad de 5 años

Le hacían una corona de flores

En nuestra aldea, Todra

se le ponía una corona en su cabeza

que llegaba a la edad de 5 años.

Todos los niños en la calle

le preparan una gran fiesta

cuando llegaba a la edad de 5

años.

En nuestra aldea, Todra.

Entonces, al homenajeado en la alegría

que llegaba a la edad de 5 años

En nuestra aldea, Todra

se lo hace entrar a la sinagoga

y se le escribe sobre una piza-

rrita de madera

en miel desde alef hasta tav

todas las letras en miel

y se le dice: querido, lame

y será la Tora dulce en la boca

como el sabor de la miel.

En nuestra aldea, Todra

en el corazón de los montes Atlas. 


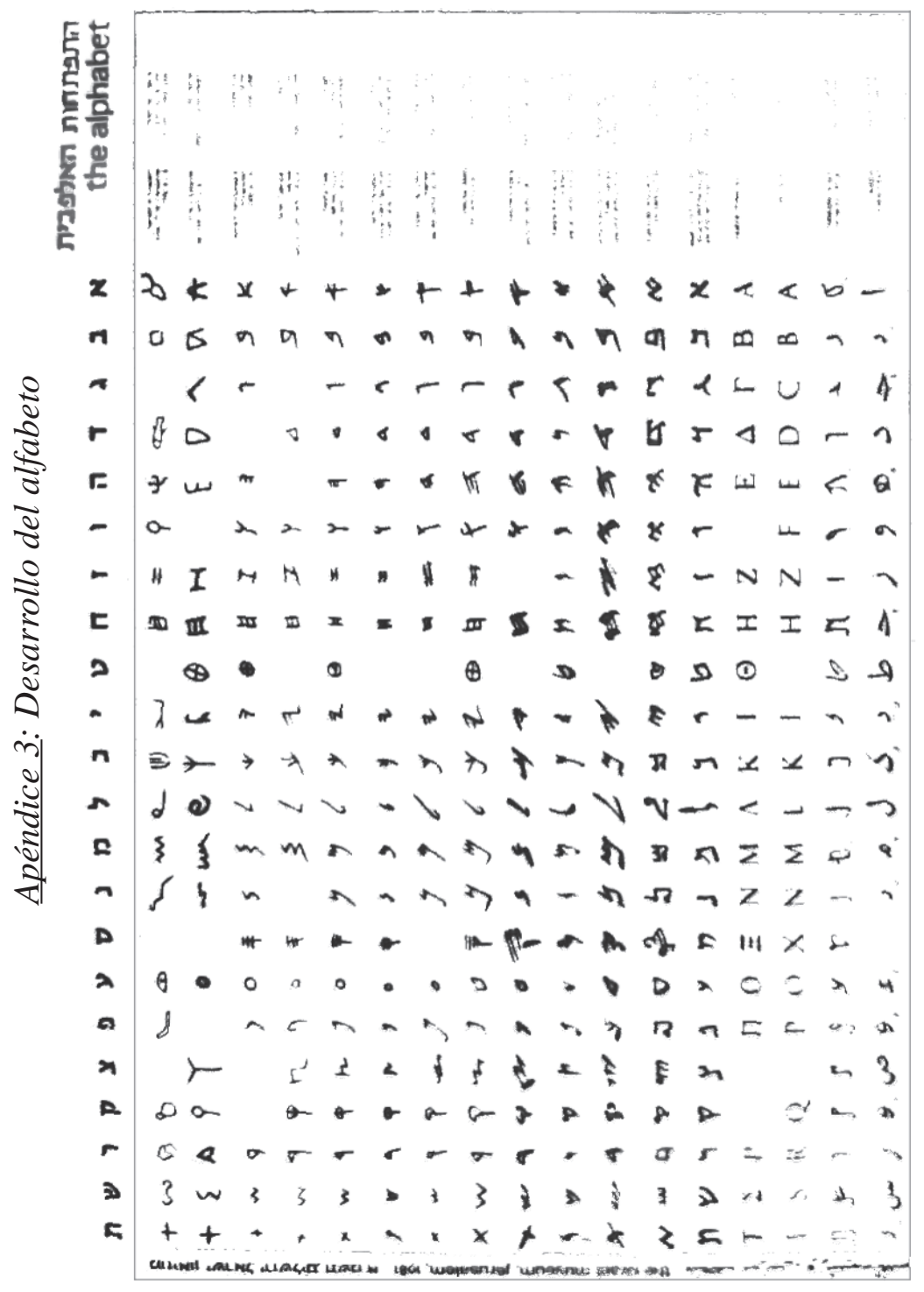




\section{REFERENCIAS}

Benjamín, Walter, 1999. "Kafka", en Iluminaciones IV, Madrid, Taurus, pp. 135-161.

Bialik, J. N. y Y. J. Ravnitzky, 2000. Sefer Haagadá, Tel Aviv, Dvir.

Jousse, Marcel, 1974. L'anthropologie du geste I, Paris, Gallimard (Voies Ouvertes).

-, 1975. L'anthropologie du geste II, La manducation de la parole, Paris, Gallimard (Voies Ouvertes).

Levinas, E., 1982. L'au-delà du verset, Paris, Minuit.

—, 1974. Autrement qu'être ou au-delà de l'essence, La Haya, Martinus Nijhoff.

Meschonnic, Henri, 1989. La rime et la vie, Paris, Verdier.

—, 1975. Le signe et le poème. Essai, Paris, Gallimard (NRF, Le Chemin).

Ouaknin, M. A., 1999. El libro quemado. Filosofía del Talmud, Barcelona, Ríopiedras.

Platón, 1995. Fedro, trad. E. Lledó, Barcelona, Planeta DeAgostini.

SAENGER, P., 2001. "La lectura en los últimos siglos de la Edad Media", en G. Cavallo y R. Chartier, Historia de la lectura en el mundo occidental, Taurus, Madrid, pp. 211-259.

Scholem, Gershom, 1988. La Cábala y su simbolismo, Buenos Aires, Editor (Colección Raíces, 11). 